Conclusions The significant incidence of fetal macrosomia in this cohort of women suggests untreated diabetes and potential benefits in adopting IADSPG criteria.

\section{PM.59 AUDIT OF THE MANAGEMENT OF PREGNANT WOMEN WITH EPILEPSY (2011)}

doi:10.1136/archdischild-2013-303966.141

N Aedla, A Duncan. Princess Royal Maternity Hospital, Glasgow, UK

The confidential enquiry into maternal deaths has highlighted 14 deaths in UK due to epilepsy (0.61 per 100,000 maternities). NICE and SIGN have set out guidelines for the management of pregnant women with epilepsy.

We conducted an audit of epilepsy management during pregnancy, comparing the results with national guidance and to a previously conducted audit in the region in 2003.

All pregnant women with epilepsy booked at our medical obstetric clinic were identified, case notes obtained, and data analysed as per our objectives.

Thirty two cases were identified and 30 case notes were obtained. Only $23 \%$ had preconception counselling and $60 \%$ had pre-pregnancy folic acid. Of these, $77 \%$ had $5 \mathrm{mg}$. Specialist referral was made in $83 \%$ of cases. $82 \%$ were on antiepileptic drugs (AEDs). Of these, $56 \%$ were on monotherapy. $26 \%$ received enzyme inducing drugs and of these only $4(50 \%)$ received $20 \mathrm{mg}$ vitamin $\mathrm{K}$ at 36 weeks. None of them received double dose steroids. $53 \%$ experienced antenatal seizures and in $66 \%$, seizure frequency was reduced or unchanged. Only $20 \%$ received anaesthetic review for reasons other than epilepsy. $50 \%$ were induced and $66 \%$ achieved a vaginal delivery. One fetus was found to have talipes at the anomaly scan. Postnatally only $32 \%$ received advice on infant care with epilepsy.

We propose an antenatal proforma for care of pregnant epileptic women. We also propose a postnatal information leaflet advising women on, breast feeding, infant care, importance of AEDs in the postnatal period, contraception and prepregnancy folic acid in subsequent pregnancies.

\section{PM.60 EFFECTS OF LMWH PROPHYLAXIS ON THE MORBIDLY OBESE PREGNANT WOMEN}

doi:10.1136/archdischild-2013-303966.142

${ }^{1}$ SK Ismail, ${ }^{2} \mathrm{~L}$ Norris, ${ }^{3} \mathrm{~S}$ O'Shea, ${ }^{1} \mathrm{JR}$ Higgins. 'Anu Research Centre, Dept of Obstetrics and Gynaecology, University College Cork, Cork University Maternity Hospital, Cork,

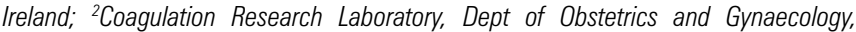
Trinity Centre for Health Sciences, St. James' Hos, Dublin, Ireland; 'Comprehensive Coagulation Centre, Department of Haematology, Cork University Hospital, Cork, Ireland

Background LMWH prophylaxis has been recommended for morbidly obese pregnant women $\left(>40 \mathrm{~kg} / \mathrm{m}^{2}\right)$. However, no data exists on the anticoagulant effects of LMWH in this group.

Aim We investigated different dosing regimens; fixed dose versus weight adjusted dose on the anticoagulant effects of the LMWH, tinzaparin used for thromboprophylaxis in obese pregnant women. Method Twenty morbidly obese pregnant women were started on a fixed dose of tinzaparin (4,500 iu/day)at 30 weeks gestation and then changed to a weight adjusted dose (75 iu/ $/ \mathrm{kg} /$ day) for the remainder of their pregnancy. Four hour post dose venous blood were taken after each initial dose and repeated every 2 weeks until delivery. Twenty normal weight women at the same gestation were used as controls.

Result Prior to LMWH prophylaxis, TFPI levels in the obese group at 30 weeks were significantly lower $(p<0.001)$ and ETP and peak thrombin levels in obese group were significantly higher compared with controls $(\mathrm{P}<0.0001 ; \mathrm{P}<0.001)$.
Within the obese group, there was no significant difference between ETP levels before and after fixed LMWH dose. However, ETP levels were significantly lower post weight-adjusted dose (75 iu/kg tinzaparin) compared with post fixed dose. There was a significant effect of LMWH on TFPI levels, $(p<0.0001)$. ETP correlated positively with total body weight at fixed dose $(r=0.578)$ $(\mathrm{p}<0.05)$.

Conclusion Morbidly obese pregnant women have increased thrombin generation and reduced natural anticoagulant in third trimester. The prothrombotic state in pregnant morbidly obese women was substantially attenuated by weight adjusted but not at fixed LMWH doses.

\section{PM.61 THE USE OF QUANTITATIVE FETAL FIBRONECTIN TO PREDICT OBSTETRIC OUTCOME: A COMPARISON OF A NEW AND ESTABLISHED QUANTITATIVE BEDSIDE ANALYSER IN ASYMPTOMATIC HIGH-RISK WOMEN}

doi:10.1136/archdischild-2013-303966.143

N Vousden, N Hezelgrave, D Abbott, A Shennan. Division of Womens Health, Kings College London, Women's Health Academic Division of Womens Health, Kings College London, London, UK

Background Preterm birth (PTB) remains a significant cause of neonatal morbidity and mortality. The most accurate predictors of PTB are ultrasound determined cervical length (CL) and fetal fibronectin (fFN) ${ }^{1}$. Quantitative fFN can be used to further outline risk in symptomatic women ${ }^{2}$. New devices are appearing on the market. Objectives To compare the capacity of two different quantitative fetal fibronectin (fFN) systems to predict cervical shortening in asymptomatic women at high-risk of PTB.

Methods Women underwent CL measurement and fFN testing between $20^{+0}$ and $24^{+6}$ week of gestation in the Preterm Surveillance Clinic at St. Thomas' Hospital (August to November 2012). Fetal fibronectin samples were run using a bedside immunoassay system (100 system, Hologic, Marlborough) and bedside chemiluminescence system (DryLab, Audit Diagnostics, Ireland).

Results 130 fFN tests were taken from 89 women. Comparison of all test results showed considerable difference between methods $\left(R^{2} 0.22\right)$. A short cervix $(<25 \mathrm{~mm})$ was found in 14 women. The 100 system was able to significantly detect cervical shortening (Area under the curve 0.69, 95\% CI 0.57-0.82, $\mathrm{p}=0.002$ ), however DryLab system could not (AUC $0.52,95 \%$ CI $0.35-0.71, p=0.12$ ). Hologic 100 had a better positive predictive value than DryLab ( $29 \%$ vs. $22 \%$ respectively), but similar negative predictive values ( $88 \%$ vs $87 \%$ respectively). Secondary outcomes such as gestational age at delivery will be presented.

Conclusion Quantitative fFN is associated with cervical shortening and therefore risk of imminent preterm birth in asymptomatic women. Not all commercial devices are accurate.

\section{REFERENCES}

1. Bolt LA, Chandiramani M, De Greef A, Seed PT, Kurtzman J \& Shennan AH. The Value of combined cervical length measurement and fetal fibronectin testing to predict spontaneous preterm birth in asymptomatic high-risk women. J Matern Fetal Neonatal Med 2011;24(7):928-932.

2. Abbott DS, Radford SK, Seed OT, et al. Evaluation of quantitative fetal fibronectin test for spontaneous preterm birth in symptomatic women. AJOG 2012.

\section{PM.62 FIVE YEAR RETROSPECTIVE REVIEW OF ANTENATAL LAMIVUDINE (LAM) TO REDUCE THE PERINATAL TRANSMISSION OF HEPATITIS B (HBV)}

doi:10.1136/archdischild-2013-303966.144

${ }^{1}$ AA Ali, ${ }^{1} \mathrm{KG}$ Glennon, 1,2BK Kelleher, 'ME Eogan, 'VJ Jackson, 'MB Brennan, 'ML Lawless, 'WF Ferguson, 1,2JL Lambert. 'Rotunda Hospital, Dublin, Ireland; ${ }^{2}$ Mater Hospital, Dublin, Ireland 